\title{
Article \\ Condition Assessment for Concrete Sewer Pipes Using Displacement Probes: A Robotic Design Case Study
}

\author{
Robert Ross ${ }^{1, *(\mathbb{D}}$, Alex Stumpf ${ }^{1} \mathbb{D}$, Dean Barnett ${ }^{2}$ and Richard Hall ${ }^{1}$ \\ 1 Department of Engineering, La Trobe University, Melbourne 3086, Australia; A.Stumpf@latrobe.edu.au (A.S.); \\ R.Hall@latrobe.edu.au (R.H.) \\ 2 Intelligent Water Networks, Melbourne 3000, Australia; Dean.Barnett@iwn.org.au \\ * Correspondence: R.Ross@latrobe.edu.au; Tel.: +61-9479-1593
}

check for

updates

Citation: Ross, R.; Stumpf, A.;

Barnett, D.; Hall, R. Condition

Assessment for Concrete Sewer Pipes Using Displacement Probes: A Robotic Design Case Study. Robotics 2021, 10, 64. https://doi.org/10.3390 /robotics10020064

Academic Editor: Giulio Reina

Received: 9 March 2021

Accepted: 26 April 2021

Published: 27 April 2021

Publisher's Note: MDPI stays neutral with regard to jurisdictional claims in published maps and institutional affiliations.

Copyright: (c) 2021 by the authors. Licensee MDPI, Basel, Switzerland. This article is an open access article distributed under the terms and conditions of the Creative Commons Attribution (CC BY) license (https:/ / creativecommons.org/licenses/by/ $4.0 /)$.

\begin{abstract}
Worldwide, millions of kilometres of sewers are constructed from concrete pipes. Unfortunately, concrete sewers are susceptible to corrosion from biogenic hydrogen sulphide, and, though they may pass visual inspection, their ability to hold together under load may be degraded. This paper presents the design of a teleoperated robot with a protractible probe, that allows an operator to apply a localised load to selected points within a concrete sewer pipe. We report findings from laboratory and field trials of our prototype, with initial results suggesting that this approach has the potential to contribute useful information to sewer maintenance planning.
\end{abstract}

Keywords: field robotics; concrete corrosion; infrastructure maintenance; condition assessment; remote sensing; sewer infrastructure

\section{Introduction}

The last half-century has seen robotic solutions being used to solve many dull, dirty and dangerous tasks [1]. These robots operate on a spectrum of autonomy from fully teleoperated to fully automated. Depending on the application some of these robotic use cases may involve the robot actively manipulating objects, whereas other applications may be simply observational-getting where it is too dangerous or constrained for humans to be. Recent inspection examples include: bridges [2], HVAC inspection [3], powerlines [4], and even wildlife [5].

Around the world, the integrity of concrete sewer infrastructure is being significantly diminished by corrosion, with estimated replacement costs of concrete sewer pipes running well into the billions of dollars (e.g., Reference [6]). This corrosion can occur quite rapidly, up to $10 \mathrm{~mm}$ per year has been identified [7]. Figure 1 shows the three main areas of these pipes which are corroded: at the obvert (top), and on each sided just above the flow line. The root cause of this corrosion was identified back in 1945 [8]. It is biogenic hydrogen sulphide, produced primarily by acidophilic aerobic sulphide-oxidising microorganisms called Acidithiobacillus thiooxidans [9].

Therefore, condition assessment of concrete pipes is a high priority for water authorities who wish to undertake preventative maintenance. Visual inspection, primarily enabled via closed circuit television (CCTV), has been used alongside other methods which can be classed into four categories: camera, acoustic, electrical, or electromagnetic [10,11]. However, the subjectivity of these methods has been criticised [12], leading to an effort to be more objective by using drill core analysis [13]. These experiments investigated the relationship between the material properties of core samples and structural strength of a concrete pipe, showing that of the remaining 'healthy' concrete, thickness is the optimal parameter, needing the smallest sampling size [14].

Unfortunately the wide-scale application of drill core analysis is limited by productivity issues. Cores drilled by hand necessarily require a person (or specially equipped robot) to enter a "confined space" which may be completely inaccessible to humans (based on size 
constraints) and given the potential for oxygen deficiency fatality, is highly regulated by occupational health and safety requirements (e.g., Reference [15]). These regulations mandate that first aid and rescue procedures can be initiated from outside the confined space as soon as possible in an emergency, which multiplies labour costs. Furthermore, drilling is a destructive testing method; each hole that is drilled in a concrete pipe must subsequently be repaired. Subject matter experts advised us that it takes over $20 \mathrm{~min}$ to drill and repair a single hole in a concrete sewer pipe. It is simply too resource intensive to deploy drill core analysis on a large scale. An alternate experimental laboratory drilling technique characterises resistance as a drill bit makes contact with the surface of the concrete [16].

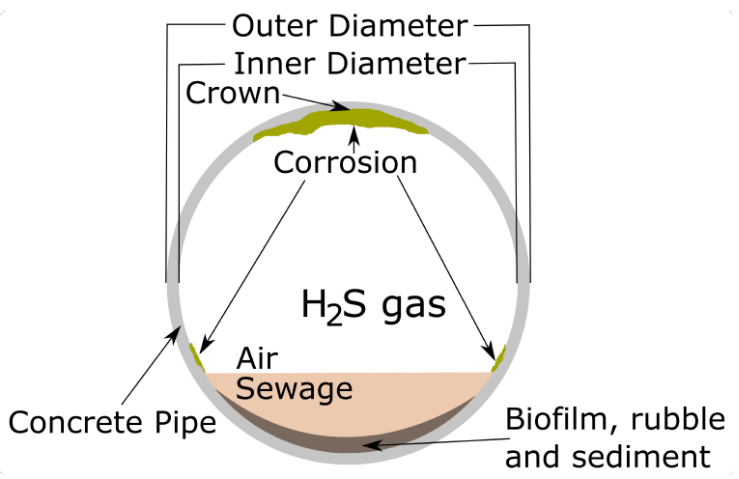

Figure 1. Cross section of a corroded concrete sewer pipe.

The productivity issues with drill core analysis can be addressed by developing a device which can rapidly measure internal diameter and physically probe through corrosion, without the need for a person to go into a concrete sewer pipe. Penetration testing involves driving an instrumented rod into a material of interest. In the 1950s, the Delft Soil Mechanics Laboratory developed the first standard for soil testing using a penetrometer [17]. As penetration testing provides a proven, simple, quick, and inexpensive means for in-situ field measurement, it has been used in many other applications [18]. Its use in the condition assessment of concrete is new.

Both the speed and the accuracy of measurement have practical operational implications. It is unnecessary to measure the diameter of a horizontal concrete pipe all along the pipe. Clearly their cylindrical shape means that one measurement would be sufficient in the presence of no erosion. Consequently, choices about where to measure need to be made. Studies have suggested that the top crown/obvert region of the pipe suffers most heavily from corrosion $[19,20]$.

Frequency of measurements also should be considered. Less measurement may allow a pipe to be assessed faster, but there will be a corresponding reduction in the amount of empirical data about a pipe. Consequently, we decided to mount a light and a camera on the robot to allow an operator to modify where samples were taken, and recommended that at a minimum, that concrete condition is assessed in pipes once every two meters (pipe segments are each $2.4 \mathrm{~m}$ long). In addition, the presence of a visual reference eliminated the need to design this robot to adapt to the changing diameter of the pipe due to the presence of debris in real-time, in contrast to previous work (e.g., Reference [21]). Whichever way the penetrometer was pointing, an operator could judge, based both on their vision and the extent of penetration, whether a surface was corroded.

Previous robots that have been designed for sewer inspection have used a range of approaches for locomotion. In 2012, Roslin categorised a number of hybrid locomotion schemes under three categories: caterpillar wall-pressed, wheeled wall-pressed, and wheeled wall-pressing screws [22]. These wall-pressing designs with sufficient actuation have been demonstrated to navigate through curves in pipes and can adapt to changes in pipe profiles [21,23]. More recently, a number of biologically-inspired locomotion approaches have been developed, e.g., as in Reference [24-26]. Such approaches have had 
considerable success in addressing design issues, such as traction, incline, variable diameter, bends, and tiny pipes.

This paper is structured as follows. In Section 2, we discuss the requirements for performing a condition assessment of concrete pipes using penetration testing. In Section 3, we discuss the design of a robotic architecture for meeting these requirements. In Section 4 , we discuss bench-scale and pilot tests of our robot. Finally, we reflect on the degree to which our requirements were met and discuss future directions in Section 5.

\section{Requirements}

We now analyse the design context in terms of the international standard ISO/IEC 25010:2011 [27] which defines a framework for system quality. Note that not all characteristics are created equal, we have summarised and omitted characteristics that were irrelevant to this design context. This framework consists of two components: the product quality model and the quality in use model. The product quality model (see Table 1) is composed of eight characteristics that relate to static and dynamic system properties. On the other hand, the quality in use model (see Table 2) is composed of five characteristics that relate to the outcome of the interaction with the system and characterises the impact that the product can have on stakeholders.

Table 1. Analysis of product quality.

\begin{tabular}{|c|c|c|}
\hline Characteristic & Sub-Characteristic & Requirements \\
\hline \multirow{3}{*}{ Functional Stability } & Functional Completeness & $\begin{array}{l}\text { Quantifies corroded concrete depth, estimates effective } \\
\text { inner pipe diameter }\end{array}$ \\
\hline & Functional Correctness & $\begin{array}{l}\text { Diameters range from } 225 \mathrm{~mm} \text { to to } 525 \mathrm{~mm} \text {, Resolution } \\
+/ /-1 \mathrm{~mm}\end{array}$ \\
\hline & Functional Appropriateness & Setup time $<5 \mathrm{~min}$, weight $<10 \mathrm{~kg}$ \\
\hline \multirow{3}{*}{ Performance Efficiency } & Time-Behaviour & Measurement time $<1 \mathrm{~min}$ \\
\hline & Resource Utilisation & Replaces expensive, slow and destructive core drilling \\
\hline & Capacity & Battery lifetime of $5 \mathrm{~h}$ \\
\hline Compatibility & Interoperability & $\begin{array}{l}\text { Can augment visual inspection, Ethernet Control } \\
\text { from PC }\end{array}$ \\
\hline \multirow{3}{*}{ Usability } & Appropriateness Recognisability & $\begin{array}{l}\text { Operators see the probe contacting the surface and } \\
\text { measurements produced }\end{array}$ \\
\hline & Learnability & Training time $<30 \mathrm{~min}$ \\
\hline & Operability & IP68 compliant (dust/waterproof) \\
\hline & User Interface Aesthetics & Laptop UI connected via CAT6 cable \\
\hline \multirow[t]{2}{*}{ Reliability } & Availability & As triggered by operator \\
\hline & Recoverability & $\begin{array}{l}\text { Watchdog on communications and power results in } \\
\text { retraction and reset }\end{array}$ \\
\hline Security & Non-Repudiation & Measurements viewable in real-time by operator \\
\hline \multirow{2}{*}{ Maintainability } & Reusability & Can be harshly washed down and redeployed \\
\hline & Testability & $\begin{array}{l}\text { Bench-scale testing with a corrosion substitute Field } \\
\text { sampling compared to camera footage }\end{array}$ \\
\hline \multirow{2}{*}{ Portability } & Adaptability & $\begin{array}{l}\text { For different sized pipes, e.g., DN225 and DN300. For } \\
\text { different sewer flow rates up to } 30 \%\end{array}$ \\
\hline & Installability & $\begin{array}{l}\text { 1. Install pull ropes from SAP1 to SAP2 (floated) } 2 \text {. } \\
\text { Attach robot to pull ropes and lower from SAP1 to start } \\
\text { of pipe }\end{array}$ \\
\hline
\end{tabular}


Table 2. Analysis of quality in use.

\begin{tabular}{ccc}
\hline Characteristics & Sub-Characteristics & Requirement \\
\hline \multirow{2}{*}{ Satisfaction } & Effectiveness & $\begin{array}{c}\text { Measures internal diameter } \\
\text { of horizontal concrete pipes. }\end{array}$ \\
\cline { 2 - 3 } & Efficiency & Test time $<1$ min. \\
\hline \multirow{2}{*}{$\begin{array}{c}\text { Freedom } \\
\text { from Risk }\end{array}$} & Usefulness & Tests concrete corrosion. \\
\hline \multirow{2}{*}{$\begin{array}{c}\text { Context } \\
\text { Coverage }\end{array}$} & Trust & Robust and accurate. \\
\cline { 2 - 3 } & Health and Safety & Cost $<\$ 30$ K per rig. \\
\hline
\end{tabular}

\section{Design}

Any robotic design with autonomy considers three robot primitives: sense, plan, and act, and define how these primitives interact [28], in addition to considering mechanical, power and user interface designs. These primitives need to be considered with respect to the environment in which the robot is expected to operate, which in our case, is a concrete sewer pipe.

Given the operational requirements and prototype nature, our approach to locomotion along the pipeline is far simpler than many of the wall-pressing schemes. Our robot is simply mounted on a polyurethane-wheeled cart which has a rope on each end that is pulled by hand. The cart is reversed out if it gets stuck. One metre intervals of rope are marked off so that the operator know when to stop and take their samples. Alternatively the robot can also be tethered to a larger robot (e.g., pipe-cleaning robot) and moved along without the separate tethering constraints. Depending on the operational requirements rope can be floated downstream and extracted at the maintenance shaft where extraction is planned. Hence, the robot can be tethered from both ends.

This simple approach was implemented as the sewer lines between successive maintenance shafts are typically straight and of uniform diameter. Hence, although the robot could be slowly driven forward by some high-torque motors, this was considered unnecessary considering the additional power and flexibility (refitting the robot for different diameters) afforded by a trolley system.

With operators able to position the system in a pipe using pull ropes at each end (without using confined space entry) or coupled to a conventional maintenance robot, the locomotion component becomes one-dimensional ( $x$-axis), which greatly simplifies our three primitives. In addition, the concrete walls of a pipe can easily damage any relatively lightweight device being pressed into it, so our main objectives are simply to sense contact and penetration, plan to move the penetrometer probe, and act to move the probe in one dimension ( $y$-axis), either towards or away from the obvert of the pipe.

For the sense component, we needed to measure distance and force. For distance, we needed to identify the start and end positions of the probe, and measure the protraction distance to a resolution of at least $1 \mathrm{~mm}$. For the start position, we mounted a ruggedised Hall-effect sensor (A3144E) which provides a soft end-stop when the probe is fully retracted. Whenever the device is repowered, (either turned on for the first time or following a power interruption), the robot does not initially know where the probe is so it retracts the probe until a known point is reached, which is when the magnets are detected by this sensor. To measure protraction distance, we mounted three magnets on the underside of the drive gear which are detected by a second Hall-effect sensor. This configuration provided a probe height measurement resolution of $0.42 \mathrm{~mm}$, well within our desired resolution of $1 \mathrm{~mm}$. We are able to determine the end position of the probe in software, simply by counting the 
number of rotations of the probe, which is highly consistent relative to our start position. Conversely, in order to measure the force component between the probe and the pipe, we attached a strain gauge load cell (Shenlan LCS $55010 \mathrm{~kg}$ load cell) (P2), which has a resolution of $\pm 5 \mathrm{~g}$. After some experimentation with different forces (data not shown), we decided on $50 \mathrm{~N}$ detected was a good indication that the probe had contacted solid concrete whilst being sufficiently small to not damage the concrete surface.

For the act component, we used a reversible drive gear to protract and retract the probe. The probe mechanism is lifted up and down by a lead-screw nut which is coupled to a waterproof motor via a pair of spur-gears. The probe mechanism slides linearly (ideally on the y-axis) in a prismatic pair fabricated from a section of aluminium extrusion and square profile of Delrin rod. This design limits rotation and requires little lubrication.

For the plan component, we used a dedicated microcontroller (ATMega328), in which its program includes two triggers for retracting the probe. First, it must be withdrawn once it has touched solid concrete as further protraction will risk the destruction of the probe. Second, it should be withdrawn once it reaches the limits of protraction because it has not detected concrete and should retract to its start position. The relationship between these two triggers can be seen in the simplified logic diagram shown in Figure 2.

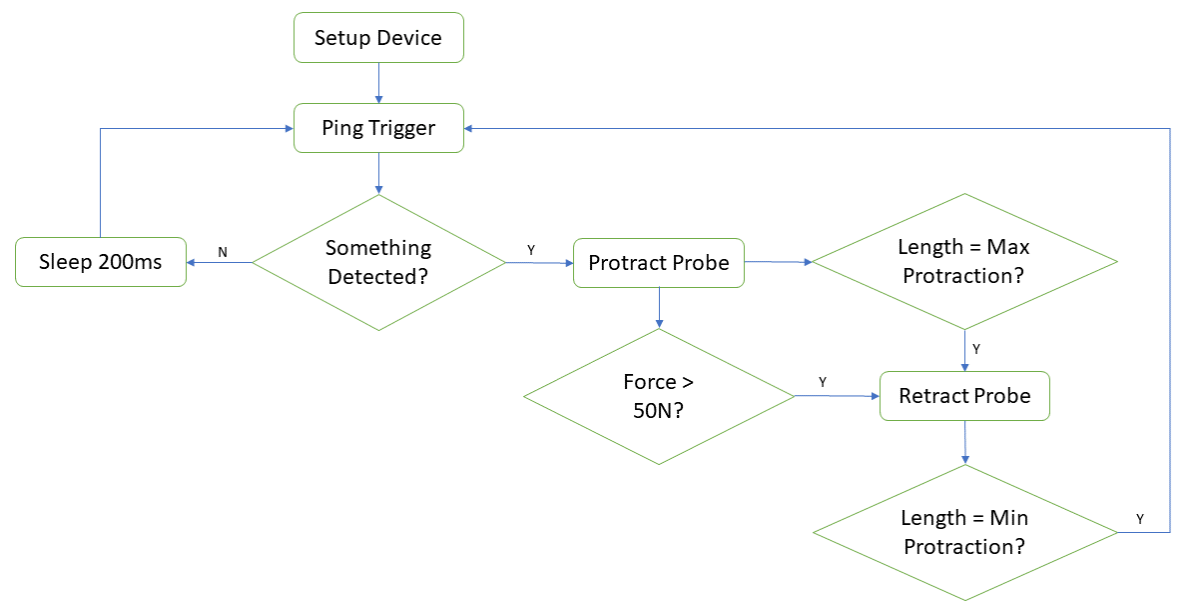

Figure 2. Sense-act logic diagram.

Figure 3 shows the system-level robot architecture with a clear delineation between the robot side and the above-ground user side. Ethernet was selected based on the high data rate, widely available waterproof ethernet cable and reasonable range $(100 \mathrm{~m})$. Long-range Ethernet modules (e.g., Longspan) could be used to increase the range as could other standards like RS-422. Although power could be externally supplied (e.g., with a Power over Ethernet (PoE) connection), we opted for an internal power to allow the robot to avoid being reset if power was externally removed.

To ensure robustness in operation and measurement (a robot with its probe wedged in a sewer would be undesirable), three measures have been designed in. During power-on, the robot initiates a start-up routine which will mitigate a situation where the probe may be stuck up inside a pipe, making removal difficult. On power-on, the motor is initiated to retract the probe until it is fully retracted. Secondly, a watch-dog timer for communications has been implemented where, if no packets have been received for a period of $5 \mathrm{~s}$, the probe will retract until fully retracted, similarly facilitating extraction of the robot. Finally, packets are numbered and include a checksum field to validate data integrity.

For the mechanical design, we needed to consider the robustness of the chassis and its height. Firstly, the robot was milled from a solid rectangular block of aluminium $(100 \mathrm{~mm} \times 300 \mathrm{~mm} \times 50 \mathrm{~mm})$ providing substantial weight $(7 \mathrm{~kg})$ and structural integrity to handle the sewer and subsequent harsh wash-down in a bleach bath. A groove was milled in the top face of the chassis and filled with neoprene rubber to ensure an IP68compliant seal when the lid is bolted down. 


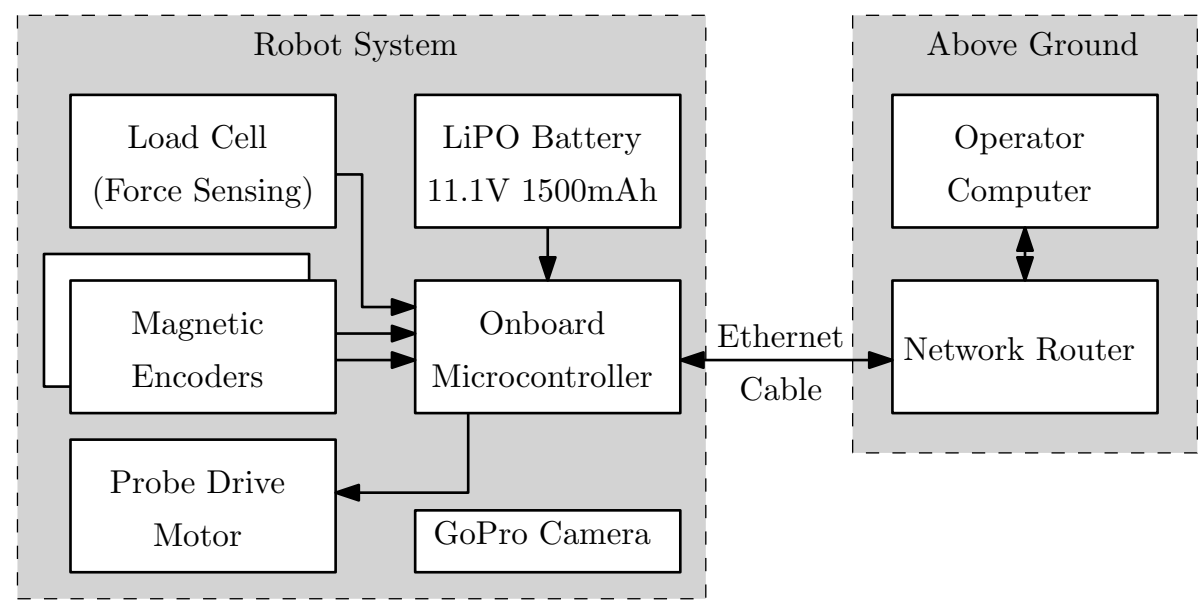

Figure 3. Robot architecture.

There are many different diameter pipes present within sewer networks, with diameters ranging from $100 \mathrm{~mm}$ through to several metres. We designed the robot to work over four different pipe diameters (DN225, DN300, DN450, and DN525) where DN corresponds to the pipe nominal diameter. The actual pipe inner diameter (ID) will vary depending on the pipe strength load class selected (higher load classes have a lower ID as they use more concrete). The different configurations (shown in Figure 4) are all field reconfigurable with a spanner and a screwdriver. The robot probing actuator has approximately $40 \mathrm{~mm}$ of travel (Figure 5 in the DN525 configuration) and can be coupled with different length probes allowing for each of the different pipe strength classes to be inspected.

For the power design, we needed to calculate our battery requirements with respect to our performance capacity requirements. Aside from the Ethernet module $(0.5 \mathrm{~W})$, servo motor ( $2.5 \mathrm{~W}$ during operation) and microcontroller $(0.15 \mathrm{~W})$ most of the components consume a negligible amount of power, leading to a total average power requirement of $1.2 \mathrm{~W}$ (assuming the servo motor is operational $20 \%$ of the time). Given that we planned a total system life of $5 \mathrm{~h}$, our power consumption produced a minimum power requirement of $6 \mathrm{Wh}$. The battery selected, a $11.1 \mathrm{~V} 1500 \mathrm{mHA}$ battery has a capacity of $16.65 \mathrm{Wh}$, leading to a theoretical runtime of over $13 \mathrm{~h}$, more than double the required runtime of $5 \mathrm{~h}$ and would easily cover a solid day worth of testing.

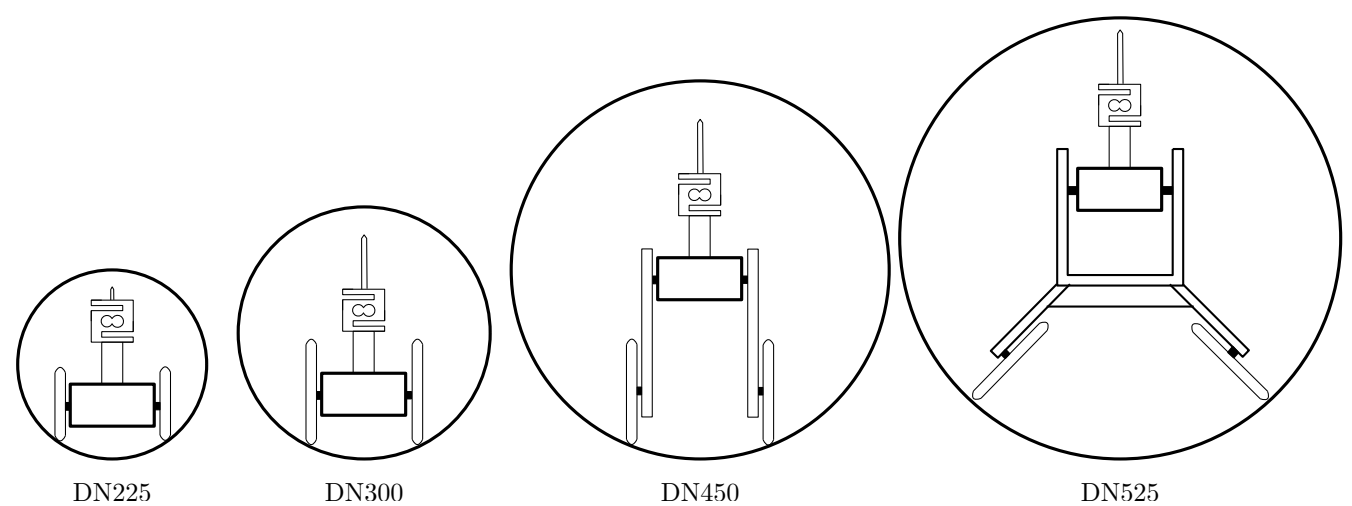

Figure 4. Robot configurations for DN225, DN300, DN450, and DN525 pipes. 


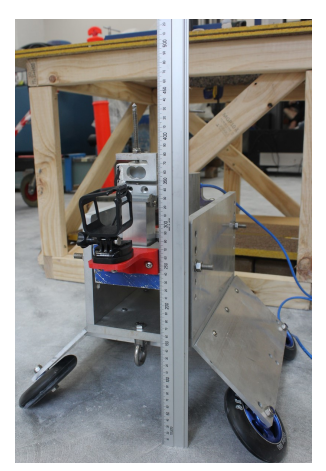

(a) Minimum.

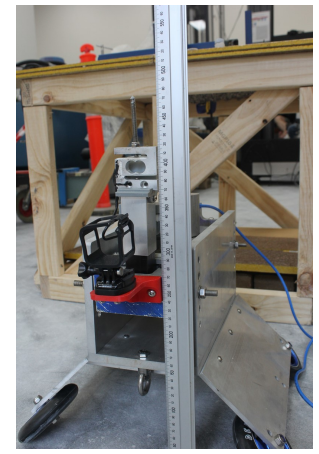

(b) Maximum.

Figure 5. Height extremes for our robot in $525 \mathrm{~mm}$ pipe configuration.

For the user interface design, we kept the input and output very simple (see Figure 6) to minimise training. After connecting to the robot (using the connect button), a user can raise or lower the lifter mechanism at a fast or slow rate. Users can also pause the current lifter mechanism position by selecting 'STOP'. Data is sent to the computer down a waterproof CAT6 Ethernet cable as a Comma Separated Variable (CSV) data stream embedded within the user datagram packet (UDP) communications protocol. The CSV file has the following five variables: unique packet id $\langle$ string $>$, battery voltage $<$ double $>$, probe protraction height $<$ double $>$, probe force $<$ double $>$, and probe retracted $<$ boolean $>$. Simultaneously, a video is also recorded over the entire run to provide more information about the condition of the concrete sewer pipe.

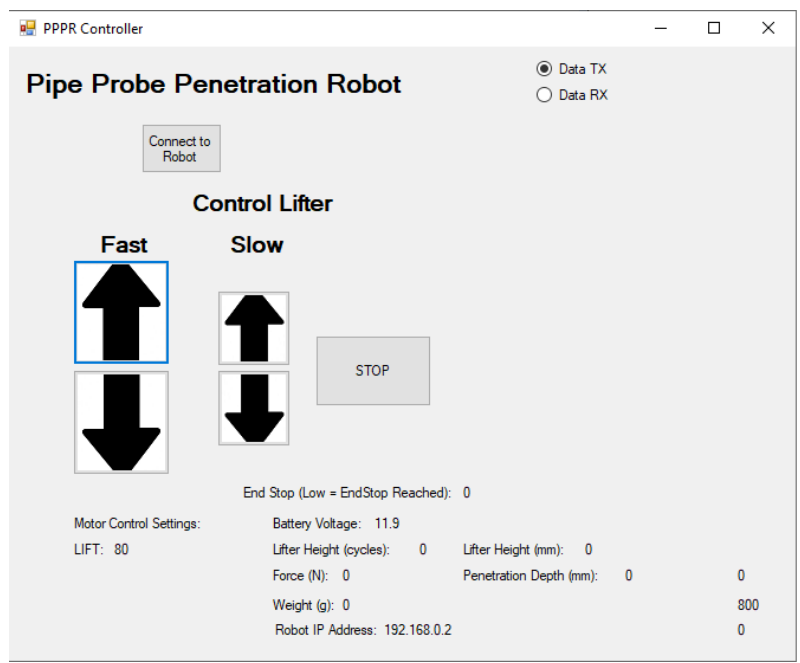

Figure 6. The user interface for our robot.

\section{Results}

We tested our robot in the laboratory with respect to its ability to consistently measure height before taking it out into the field. In order to perform these tests, we required a ground truth a reference object. We created this ground truth as a solid model in SolidWorks as a set of five step increments of $5 \mathrm{~mm}$, using the left half of the SolidWorks profile shown in Figure 7. 


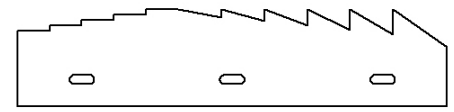

(a) Cutout Profile.

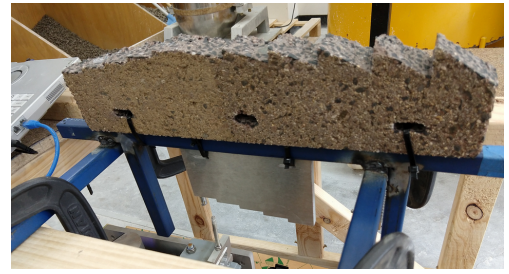

(b) Concrete (top) and Aluminium (bottom).

Figure 7. Cutouts for benchmarking the penetrometer.

Using this model, we waterjet cut out two materials to test against, selected due to their contrasting smoothness. A nice smooth aluminium surface should give consistent readings as the penetrometer would not slip on making contact with the surface. In contrast, the concrete paver was more faithful to our robot's operating environment, a concrete sewer has a very rough surface which (amongst other things) might cause the penetrometer tip to slip. We deliberately exacerbate slippage by adding a set of six angular steps (from 10-35 degrees) into the paver (right half of the SolidWorks cut-out Profile). If our robot could not survive slippage in the laboratory, it would definitely not survive in the field.

We bench-tested our robot's ability to consistently measure height using multiple tests at the various step height increments. In addition, to validate fault tolerance protocols, we ran multiple tests at the same height with induced faults as follows:

1. Two normal penetration tests are performed.

2. Trigger the robot to begin a test. Height recording starts.

3. A fault is induced (power interrupted or Ethernet disconnected) at a random height before surface contact is made. Height recording stops.

4. The fault should cause the probe to retract to its default position when power is restored or a timeout occurs.

5. Two normal penetration tests are performed.

This test forces the robot to retract the probe to the position height $=0$. Given the distance between the robot and the solid contact surface will not change, any change in the measured contact height will indicate issues either at the start point with the soft end stop and/or issues at the end point (concrete-contact) with backlash.

For the power-interrupted and Ethernet disconnection tests (Figure 8), a discontinuity in the measurements is observed as the probe retracts and the Ethernet connection re-establishes. By the time data sampling resumes (for each test), the probe is fully retracted, initialised, and ready for another test. The agreement of results from prior and post the relevant faults indicates the system has reliably re-initialised and is ready for further measurements.

Conversely, our different-height test (Figure 9) used continuous power, similar to normal operations for the robot. Each test (hill) was triggered by an operator and the robot was rolled along the $\mathrm{x}$-axis with respect to the cut-out between tests. It is evident that, as desired, our penetrometer recorded measurements of exactly $5 \mathrm{~mm}$ between the different smooth aluminium step levels, from a random starting height of $17.5 \mathrm{~mm}$ to $37.5 \mathrm{~mm}$.

In these graphs, we have also displayed recorded force on the right axis, revealing two things. First, that once our stopping criteria of $50 \mathrm{~N}$ is detected the probe begins to retract (downhill slope on the right of each uninterrupted hill). Second, that there is no evidence of slippage on these flat aluminium surfaces as expected, which would be picked up as secondary spike in the graph. We did pick up a slip in our angle tests reported elsewhere, along with a significant force profile difference between soft and solid concrete (see Reference [29]). 


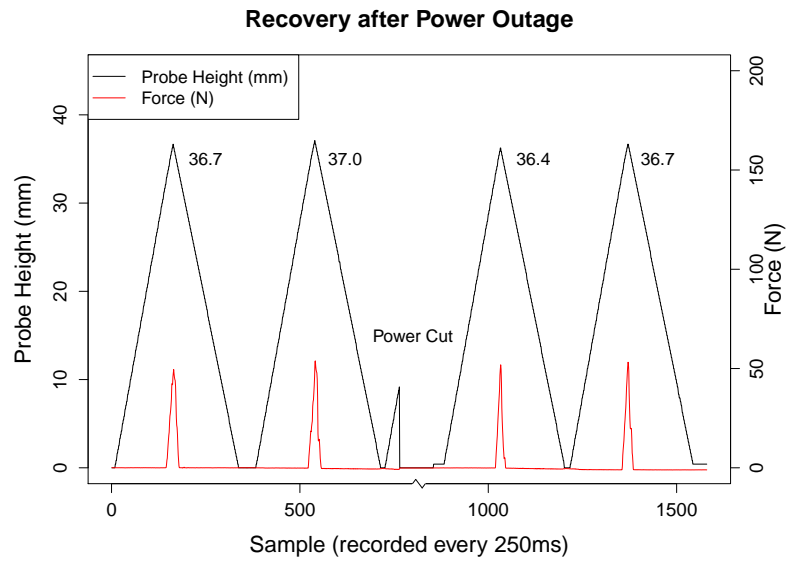

(a) Power Interruption.

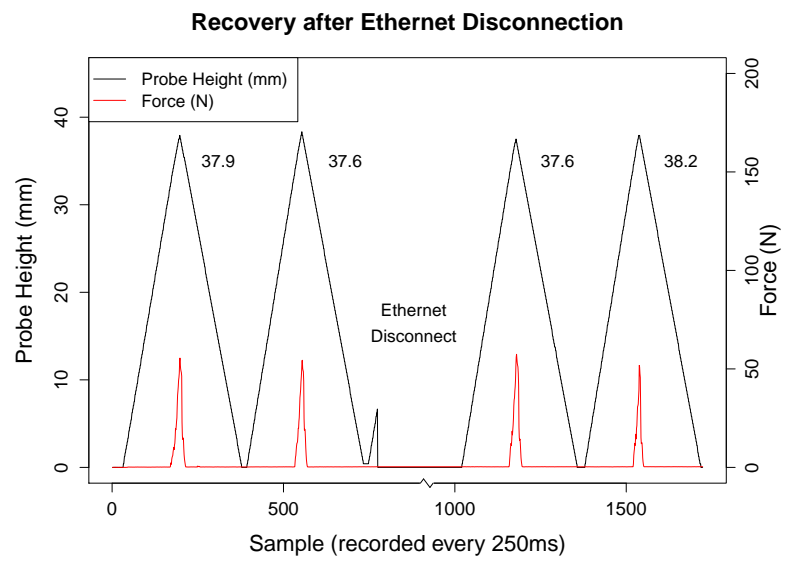

(b) Ethernet Interruption.

Figure 8. Fault tolerance validation tests. Step Test $(\mathbf{5 m m})$

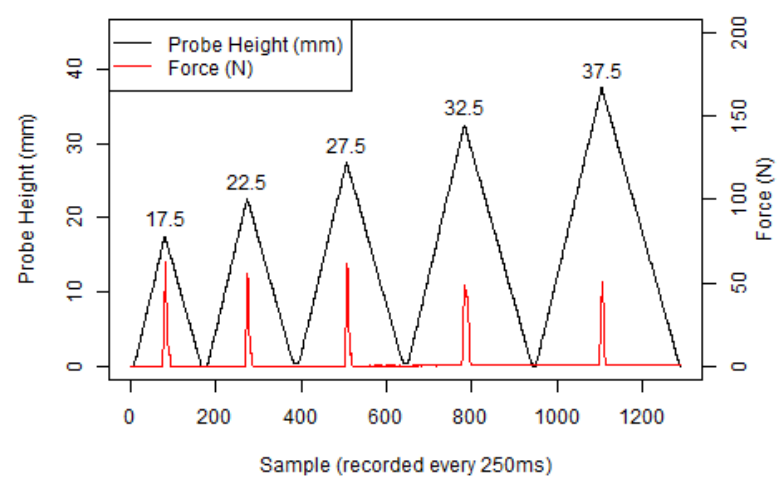

Figure 9. Penetrometer Measurement Tests.

The effective diameter of the pipe, $D$, is the inner pipe diameter consisting of solid concrete (including the distance the probe penetrates the concrete) shown in Figure 10. The effective diameter is not directly measured as there is only a probe touching the obvert of the pipe and nothing touching the invert of the pipe. $D$ can be computed as follows, although inaccuracies may be introduced if something (e.g., silt, rocks) causes the wheels to lift up:

$$
\begin{gathered}
D=s+t+e, \\
s=r-\sqrt{r^{2}-(C / 2)^{2},}
\end{gathered}
$$

where $s$ (the sagitta) corresponds to the height of the wheels above the invert of the pipe based on the chord distance, and $C$ is where the wheels make contact with the arc of the pipe. $t$ is the height of the robot's tip at full retraction above flat ground, $r$ is the nominal inner pipe radius, and $e$ is the extension of the actuator until the probe stopped, as shown in Figure 10. 


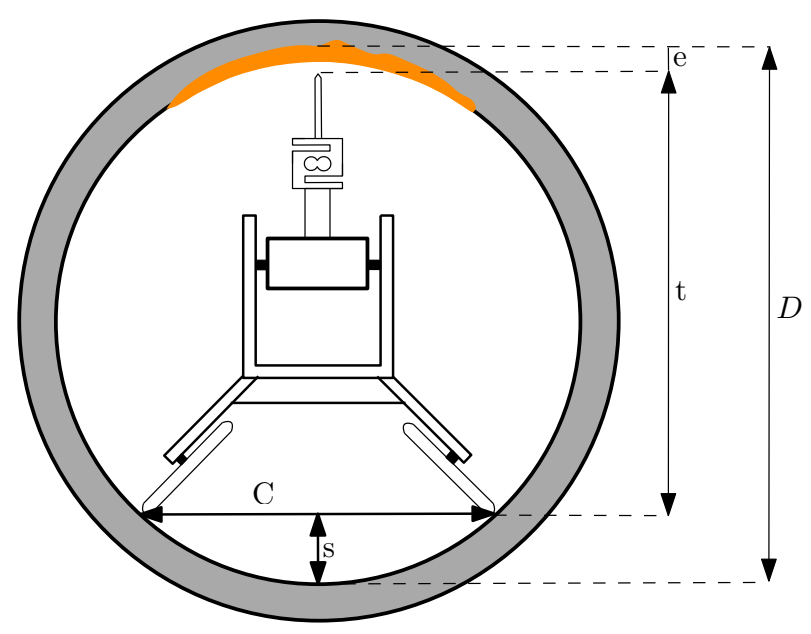

Figure 10. Effective diameter computation.

The calculated effective diameter can be applied to a known pipe to infer depth of cover over reinforcement to provide a measure of how well the reinforcement may still be protected. Hence, segments of the pipe may be targeted for re-lining or replacement.

Having characterised our penetrometer in the laboratory, we then allowed operational personnel to insert our robot into several concrete sewer pipes, inside standard procedures. We operated our devices on multiple horizontal runs with pipe diameters from $300 \mathrm{~mm}$ through to $525 \mathrm{~mm}$, on $100 \mathrm{~m}$ sections of sewer in the suburbs of Bacchus Marsh and Keysborough. Samples were taken at $1 \mathrm{~m}$, and an example of the Keysborough run is shown in Figure 11.

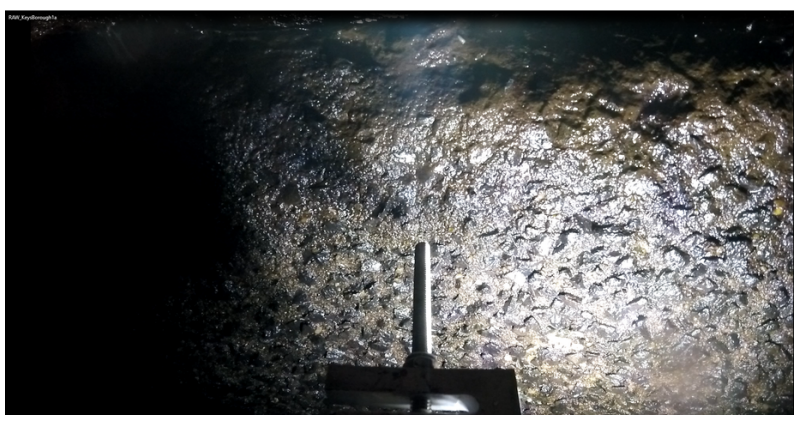

(a) Photo of concrete sewer.

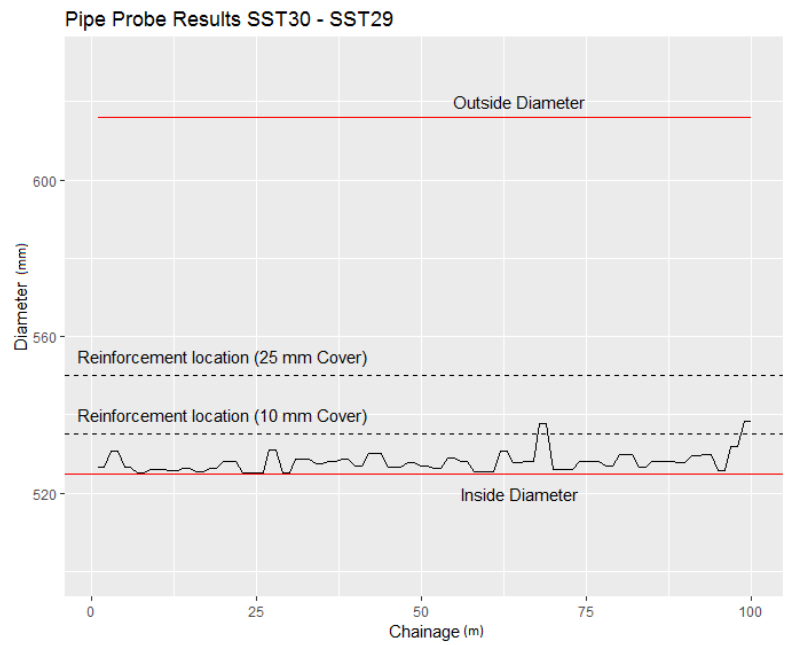

(b) Example pipe profile.

Figure 11. Profiling horizontal concrete sewer pipes.

This run is interesting to sewer maintenance practitioners for several reasons. There are two points where corrosion exceeds $10 \mathrm{~mm}$ (and for low cover reinforcement pipes may soon expose rebar), there is significant variation in corrosion over the length of the pipe and there is a fair amount of corrosion over $5 \mathrm{~mm}$. The video recordings also confirmed the penetrometer penetrated the pipe outer wall before coming to a stop when harder material was encountered. The chainage (record of how far into the pipe) also allows more degraded parts to be identified and potentially individually remediated. Field results significantly indicated, the maximum amount of time required to take an individual sample was less than $30 \mathrm{~s}$, compared to a drill core analysis sample time of $20 \mathrm{~min}$. 


\section{Conclusions}

In this paper, we presented the design and validation of a teleoperated robot with a protractible probe, that allows an operator to rapidly apply a localised load to selected points within a concrete sewer pipe to test its structural integrity. We now consider the extent to our requirements were met and discuss future directions in which we are taking this work. In terms of meeting our requirements, we refer back to our requirements columns in the two tables Product Quality (Table 1) and Quality in Use (Table 2).

In terms of quality of use, we developed a robot that could measure the internal pipe diameter of a concrete sewerage pipe in under one minute per test without requiring confined-space entry to a sewer. Consequently, we are able to claim that our overall objective was largely achieved, that is, our robot can physically detect corrosion in horizontal concrete pipes. Nonetheless, our robot requires more work. Our robot uses depth measurement as a proxy for corrosion, and can correctly detect corrosion whenever the distance between the floor-ceiling is an outlier with respect to the average height. However, our robot cannot detect corrosion in the instance where height of rubble or debris on the floor of the concrete pipe (elevating its wheels off the pipe surface) matches or exceeds the depth of corrosion in the obvert of the pipe. Additionally, we can currently only probe one point (the obvert), which is where the corrosion typically is most severe. Aside from depth measurement, we minimised system costs where possible, while building for the harsh sewer environment, and the total materials costs for building this robot came to $\$ 20 \mathrm{~K}$. And we successfully completed field testing on $100 \mathrm{~m}$ lengths of concrete sewer pipe.

In terms of product quality, our robot's maximum protraction extension and retraction time satisfied the time behaviour requirement, our system lifetime exceeded the minimum life, and the system was IP68 compliant. The system was reasonably portable, coming in at $7 \mathrm{~kg}$ in total, and easily installable through a sewer access point using ropes or a coupled inspection robot. Once it finished its work in the sewer, the robot was cleaned with pressurised water and a bleach bath, which has not adversely effected its operation.

Our robot was able to rapidly measure concrete pipe degradation and with the ropetethered approach does not require confined space entry. The productivity gains of using such a tool, therefore, gives sewer maintenance planners a capability of improving the quality of data on sewer degradation. This information is critical to making informed decisions about remediation works, given the cost of these assets. Our industry partners are currently investigating feasibility for a second version of this robot with capability of larger sewer sizes and with multiple probing angles.

Author Contributions: Conceptualization, R.R., D.B.; methodology, R.R., A.S.; software, R.R.; validation, R.R., A.S., D.B.; investigation, R.R., D.B., A.S., R.H.; resources, D.B.; data curation, R.R., R.H.; writing-original draft preparation, R.R. and R.H.; writing-review and editing, R.R., R.H. All authors have read and agreed to the published version of the manuscript.

Funding: This research was funded in partnership with IWN.

Institutional Review Board Statement: Not applicable.

Informed Consent Statement: Not applicable.

Data Availability Statement: Full dataset not available as it details operational aspects of current critical infrastructure.

Acknowledgments: This research was conducted with funding from Intelligent Water Networks (IWN) expert domain advice from Western Water and CMP Consulting Group. Western Water and South East Water facilitated in-sewer pipe testing. We specifically thank Soyun Punyadasa, Owen Harris, Duncan Sinclair and John Garton.

Conflicts of Interest: The authors declare no conflict of interest. 


\section{References}

1. Fishel, J.A.; Oliver, T.; Eichermueller, M.; Barbieri, G.; Fowler, E.; Hartikainen, T.; Moss, L.; Walker, R. Tactile Telerobots for Dull, Dirty, Dangerous, and Inaccessible Tasks. In Proceedings of the 2020 IEEE International Conference on Robotics and Automation (ICRA), Paris, France, 20-24 May 2020; pp. 11305-11310.

2. Sutter, B.; Lelevé, A.; Pham, M.T.; Gouin, O.; Jupille, N.; Kuhn, M.; Lulé, P.; Michaud, P.; Rémy, P. A semi-autonomous mobile robot for bridge inspection. Autom. Constr. 2018, 91, 111-119. [CrossRef]

3. Beckett, A.; Ross, R. PyroShield-A HVAC fire curtain testing robot. Autom. Constr. 2017, 81, 234-239. [CrossRef]

4. Richard, P.L.; Pouliot, N.; Morin, F.; Lepage, M.; Hamelin, P.; Lagac, M.; Sartor, A.; Lambert, G.; Montambault, S. LineRanger: Analysis and Field Testing of an Innovative Robot for Efficient Assessment of Bundled High-Voltage Powerlines. In Proceedings of the 2019 International Conference on Robotics and Automation (ICRA), Montreal, QC, Canada, 20-24 May 2019; pp. 9130-9136.

5. Ross, R.; Carver, S.; Browne, E.; Thai, B.S. WomBot-An exploratory robot for monitoring wombat burrows. SN Appl. Sci. 2021, in press.

6. United States Environmental Protection Agency. Clean Watersheds Needs Survey: Report to Congress. EPA-832-R-10-002; EPA: Washington, DC, USA, 2008. Available online: https://www.epa.gov/sites/production/files/2015-06/documents/cwns2008rtc. pdf (accessed on 1 March 2021).

7. Zhang, L.; De Schryver, P.; De Gusseme, B.; De Muynck, W.; Boon, N.; Verstraete, W. Chemical and biological technologies for hydrogen sulfide emission control in sewer systems: A review. Water Res. 2008, 42, 1-12. [CrossRef] [PubMed]

8. Parker, C. The corrosion of concrete: 2. the function of thiobacillus concretivorus (nov. spec.) in the corrosion of concrete exposed to atmospheres containing hydrogen sulphide. Aust. J. Exp. Biol. Med Sci. 1945, 23, 91-98. [CrossRef]

9. Vollertsen, J.; Nielsen, A.H.; Jensen, H.S.; Wium-Andersen, T.; Hvitved-Jacobsen, T. Corrosion of Concrete Sewers-The Kinetics of Hydrogen Sulfide Oxidation. Sci. Total. Environ. 2008, 394, 162-170. [CrossRef]

10. Lai, F.; Feeney, C. Condition Assessment of Wastewater Collection Systems; EPA Science Forum: Washington, DC, USA, 2008.

11. Liu, Z.; Kleiner, Y. State of the art review of inspection technologies for condition assessment of water pipes. Measurement 2013, 46, 1-15. [CrossRef]

12. Dirksen, J.; Clemens, F.; Korving, H.; Cherqui, F.; Le Gauffre, P.; Ertl, T.; Plihal, H.; Müller, K.; Snaterse, C. The consistency of visual sewer inspection data. Struct. Infrastruct. Eng. 2013, 9, 214-228. [CrossRef]

13. Stanic, N.; Haan, C.; Tirion, M.; Langeveld, J.; Clemens, F. Comparison of core sampling and visual inspection for assessment of sewer pipe condition. In Proceedings of the 9th International Conference on Urban Drainage Modelling, Belgrade, Serbia, 4-6 September 2012.

14. Stanić, N.; Langeveld, J.; Salet, T.; Clemens, F. Relating the structural strength of concrete sewer pipes and material properties retrieved from core samples. Struct. Infrastruct. Eng. 2017, 13, 637-651. [CrossRef]

15. Australian Government, Department of Employment. Work Health and Safety (Confined Spaces) Code of Practice; Safe Work Australia, Australia 2015. Available online: https:/ / www.legislation.gov.au/Details/F2016L00405 (accessed on 1 March 2021)

16. Giovanangeli, N.; Piyathilaka, L.; Kodagoda, S.; Thiyagarajan, K.; Barclay, S.; Vitanage, D. Design and development of drillresistance sensor technology for accurately measuring microbiologically corroded concrete depths. In Proceedings of the International Symposium on Automation and Robotics in Construction-ISARC, Banff, AB, Canada, 21-24 May 2019; Volume 36, pp. 735-742.

17. Schaap, L.H.; Föhn, P.M. Cone penetration testing in snow. Can. Geotech. J. 1987, 24, 335-341. [CrossRef]

18. Perumpral, J. Cone penetrometer applications-A review. Trans. ASAE 1987, 30, 939-0944. [CrossRef]

19. Islander, R.L.; Devinny, J.S.; Mansfeld, F.; Postyn, A.; Shih, H. Microbial ecology of crown corrosion in sewers. J. Environ. Eng. 1991, 117, 751-770. [CrossRef]

20. Sydney, R.; Esfandi, E.; Surapaneni, S. Control concrete sewer corrosion via the crown spray process. Water Environ. Res. 1996, 68, 338-347. [CrossRef]

21. Park, J.; Hyun, D.; Cho, W.H.; Kim, T.H.; Yang, H.S. Normal-force control for an in-pipe robot according to the inclination of pipelines. IEEE Trans. Ind. Electron. 2010, 58, 5304-5310. [CrossRef]

22. Roslin, N.S.; Anuar, A.; Jalal, M.F.A.; Sahari, K.S.M. A review: Hybrid locomotion of in-pipe inspection robot. Procedia Eng. 2012, 41, 1456-1462. [CrossRef]

23. Horodinc $\breve{A}$, M.; Preumont, A.; Burda, I. The heli-pipe inspection robots architecture for curved pipes. In Proceedings of the International Conference of Manufacturing Systems ICMS, Montreal, QC, Canada, 24-30 August 2003; pp. 149-154.

24. Mano, Y.; Ishikawa, R.; Yamada, Y.; Nakamura, T. Development of contraction force control system of peristaltic crawling robot for sewer pipe inspection. In Proceedings of the 2018 IEEE/ASME International Conference on Advanced Intelligent Mechatronics (AIM), Auckland, New Zealand, 9-12 July 2018; pp. 936-941.

25. Xavier, M.S.; Fleming, A.J.; Yong, Y.K. Experimental Characterisation of Hydraulic Fiber-Reinforced Soft Actuators for Worm-Like Robots. In Proceedings of the 2019 7th International Conference on Control, Mechatronics and Automation (ICCMA), Delft, The Netherlands, 6-8 November 2019; pp. 204-209.

26. Venkateswaran, S.; Chablat, D.; Boyer, F. Numerical and experimental validation of the prototype of a bio-inspired piping inspection robot. Robotics 2019, 8, 32. [CrossRef] 
27. ISO/IEC. 25010:2011, Systems and Software Engineering—Systems and Software Quality Requirements and Evaluation (SQuaRE)System and Software Quality Models; ISO/IEC: Geneva, Switzerland, 2011.

28. Murphy, R.R. Introduction to AI Robotics, 1st ed.; MIT Press: Cambridge, MA, USA, 2000.

29. Ross, R.; Baji, A.; Barnett, D. Inner Profile Measurement for Pipes Using Penetration Testing. Sensors 2019, 19, 237. [CrossRef] [PubMed] 